\title{
D 型新简支便梁结构分析
}

\author{
Structure Analysis of D-type Newly Simply Supported Stool Beam \\ 张维烈 ${ }^{1}$ 刘政豪 ${ }^{2}$ \\ Weilie Zhang ${ }^{1}$ Zhenghao Liu $^{2}$
}

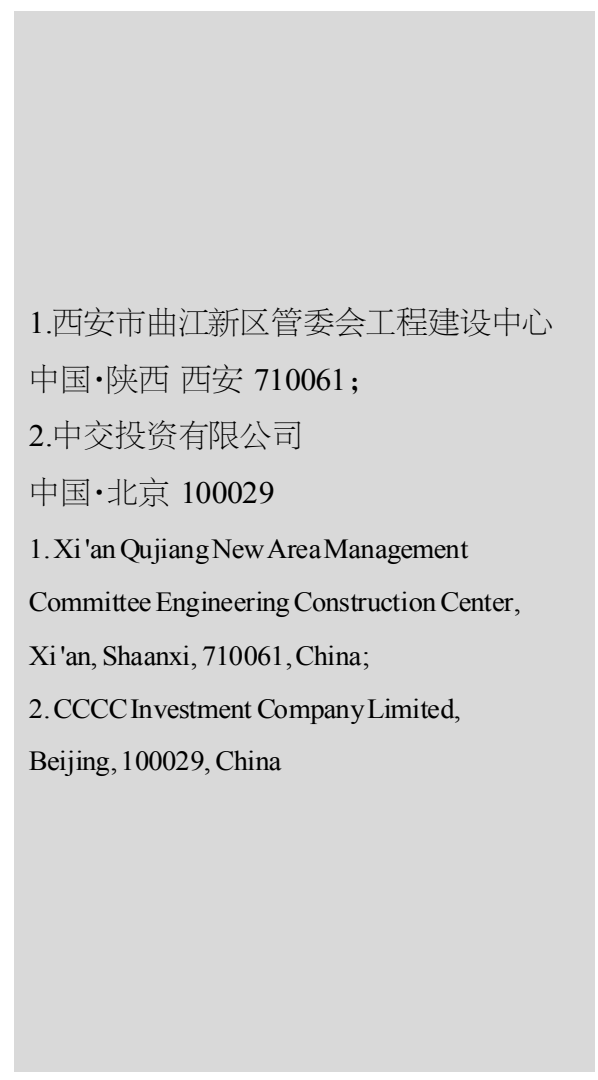

【摘 要】新型 $12 \mathrm{~m}$ 施工便梁适用于新建桥梁下穿既有铁路线施工, 单跨使用跨度为 $10 \mathrm{~m}$ 。 根据施工需要纵梁可拼接组成多跨连续梁, 同时, 采用横抬梁支撑。通过对常规的施工便 梁进行优化改进, 新 D 型施工便梁不仅安全而且施工更加便捷, 有效提高施工效率。基于 有限元理论对新 $\mathrm{D}$ 型简支施工便梁进行系统分析, 通过计算该新型简支便梁的承载力及 稳定性, 研究结果证明 D 型新简支便梁安全可靠、经济便捷, 为今后新建桥梁跨线施工提 供了理论支撑和有效指导作用。

【Abstract \The new $12 \mathrm{~m}$ construction beam is suitable for the construction of the new bridge under the existing railway line, with a single span of $10 \mathrm{~m}$. According to the construction needs, the longitudinal beam can be spliced to form a multi-span continuous beam, which is supported by transverse beam. Through the optimization and improvement of the conventional construction beam, the new d-type construction beam is not only safe, but also more convenient and effective to improve the construction efficiency. Based on the finite element theory, this paper makes a systematic analysis of the new d-type simply supported beam in construction, and calculates the bearing capacity and stability of the new d-type simply supported beam. The research results prove that the d-type simply supported beam is safe, reliable, economical and convenient, which provides theoretical support and effective guidance for the construction of new Bridges in the future.

【关键词】简支便梁; 承载力; 稳定性;纵梁;横抬梁

【Keywords】simply supported stool beam; bearing capacity; stability; longitudinal beam; transverse beam

【DOI \10.36012/etr.v2i1.967

\section{1 引言}

简支施工便梁的工作原理是在需要跨越交通线路的两侧 建立临时支撑, 然后在临时支撑上方安置 $\mathrm{D}$ 型简支施工便梁 ${ }^{[1]}$ 这种结构形式的加固维修施工等工作简单便捷, 同时, 施工效 率大大提高, 施工结束只需要拆除便梁即可恢复通行。一般 $12 \mathrm{~m}$ 新 $\mathrm{D}$ 型施工便梁的主要性能包括线间距满足 $4 \sim 5.5 \mathrm{~m}$, 适 用于道砟厚度 $\geqslant 75 \mathrm{~cm}$ 的线路, 横梁间距统一按 $670 \mathrm{~mm}$, 横抬 梁采用焊接箱型结构, 长度为 $12 \mathrm{~m}$; 横抬梁垂直于纵梁设置,
其间距 $\leqslant 9 \mathrm{~m}$; 横抬梁的跨度 $\leqslant 7.6 \mathrm{~m}$, 可横抬线间两片纵梁。新 型施工便梁的出现使得地道桥施工更加方便快捷, 保证施工 的安全可靠。

\section{D 型施工便梁结构}

\section{1 计算参数}

钢材自重 $78.5 \mathrm{kN} / \mathrm{m}^{3}$; 容许应力 $\mathrm{Q} 345 \mathrm{~B}$ : 弯曲容许应力为 $210 \mathrm{MPa}$, 轴向应力为 $200 \mathrm{MPa}$, 剪应力为 $120 \mathrm{MPa}$; 钢材弹性 模量取 $2.1 \times 105 \mathrm{MPa}$; 剪切模量取 $8.1 \times 104 \mathrm{MPa}$; 泊松比为 0.3 ; 
道路桥梁工程 Road and Bridge Engineering

列车荷载: CH-NL( NL-活载)汽车冲击系数取 1.3 。

\section{2 简支便梁结构图}

根据现场情况, 并结合现有线路间距及施工便梁构造, 施 工便梁平面布置图及横断面如图 1 和图 2 所示。

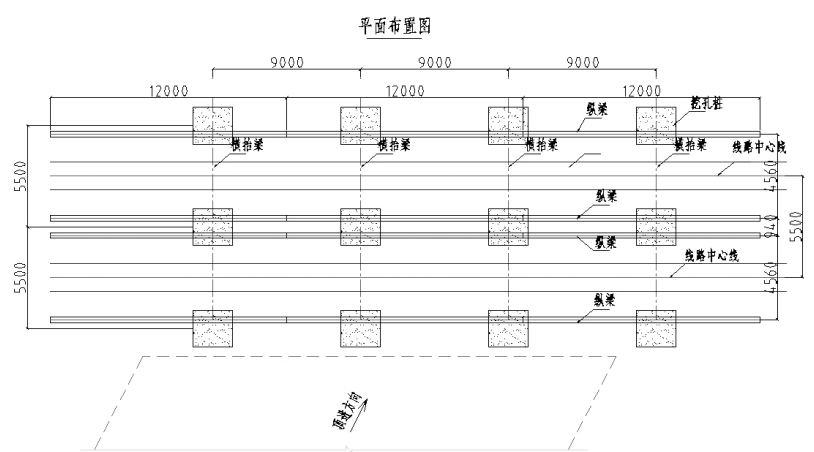

图 1 平面布置图 (单位: $\mathrm{mm}$ )

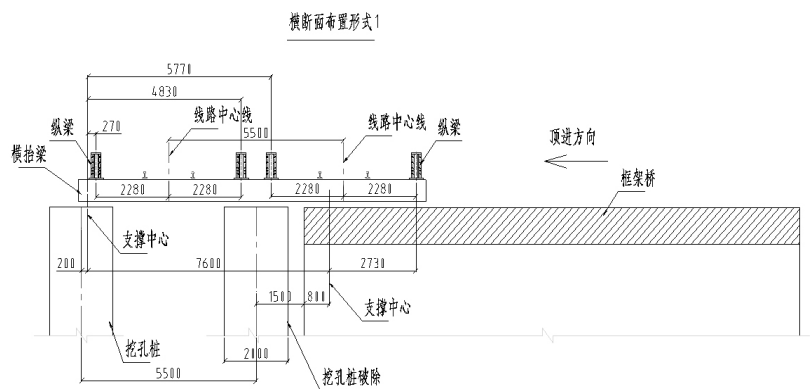

图 2 横断面布置图 (单位: $\mathrm{mm}$ )

\section{$3 \mathrm{D}$ 型施工便梁结构分析}

\section{1 模型建立}

根据 $12 \mathrm{~m}$ 施工便梁施工图可知, 横抬梁间距为 $9 \mathrm{~m}$, 建立 单跨 $9 \mathrm{~m}$ 简支便梁模型, 其离散图如图 3 所示。其中, 纵、横梁 之间共节点, 横抬梁和纵梁之间通过弹性连接约束, 横抬梁与 桩顶连接部位按铰接处理。

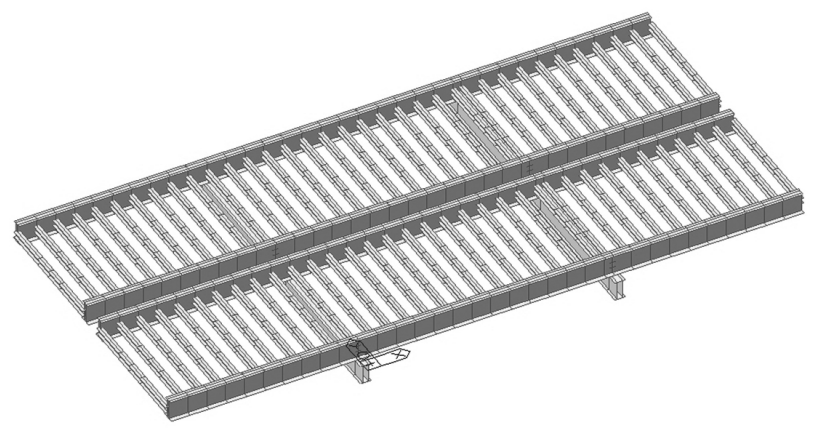

图 3 单跨 9m 简支便梁模型离散图

\section{2 结构计算分析}

通过对模型加载进行其承载力和稳定性验算, 加载类型 包括移动荷载和荷载组合，检验荷载作用下简支便梁的结构
是否满足规范要求 ${ }^{[2]}$

\section{2 .1 整体受力分析}

移动荷载下单跨 $9 \mathrm{~m}$ 简支便梁位移情况如图 4 所示。
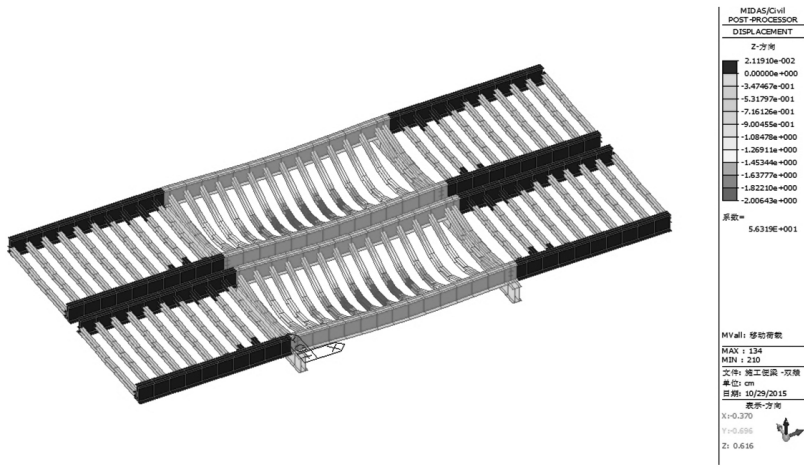

图 4 移动荷载下单跨 $9 \mathrm{~m}$ 简支便梁位移图 (单位: $\mathrm{mm}$ )

由上图 4 可知, 移动荷载作用下, 纵梁最大位移为 $1.83 \mathrm{~mm}<9000 / 900=10 \mathrm{~mm}$, 纵梁刚度满足规范要求。标准组合 下单跨 $9 \mathrm{~m}$ 简支便梁横梁最大弯曲应力 $233.2 \mathrm{MPa}$ 大于弯曲 容许应力 $210 \mathrm{MPa}$; 最大剪应力为 $98.2 \mathrm{MPa}$ 小于容许剪应力 $120 \mathrm{MPa}_{0}$ 。因为该施工便梁为临时结构, 横梁最大弯曲应力为 233.2MPa, 小于弯曲应力设计值 $295 \mathrm{MPa}$, 所以该结构安全。

3.2 .2 横抬梁稳定性及抗倾覆分析

对于单跨 $9 \mathrm{~m}$ 简支便梁, 单线列车荷载作用下制动力: $T=$ $0.1 \times(220 \times 5+92 \times 1.5)=123.8 \mathrm{kN}$ 。根据板单元网格划分结果: 每 个接触面按 9 个节点荷载考虑, 则每个节点荷载 $f=(2 \times 128.8)$ $/(4 \times 9)=6.9 \mathrm{kN}$, 横抬梁底部与桩顶为螺栓连接按铰接处理。建 立横抬梁板单元模型如图 5 所示。

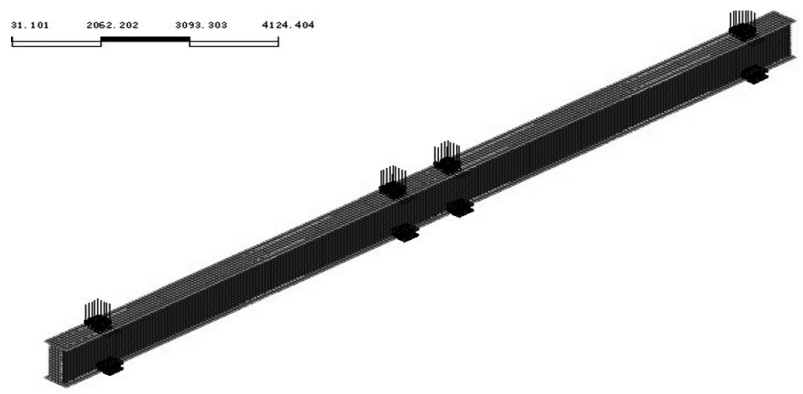

图 5 横抬梁板单元模型离散图

由图 5 可知, 制动力作用下横抬梁最大位移为 $1.01 \mathrm{~mm}$, $\mathrm{TOP}$ 面最大范梅塞斯应力为 $116.9 \mathrm{MPa}$, TOP 面最大剪应力为 $61.8 \mathrm{MPa}$ 。 BOT 面最大范梅塞斯应力为 $158.4 \mathrm{MPa}$, BOT 面最大 剪应力为 $76.3 \mathrm{MPa}$, 满足规范要求。制动力作用下横抬梁一阶 屈曲稳定系数为 29.7 大于经验系数 4.0 , 则整体稳定性满足 要求。

在单线列车荷载作用下, 制动力 $T=123.8 \mathrm{kN}$ 。标准组合 下, 横抬梁最小支反力 $N=673.7 \mathrm{kN}$ 。单线列车荷载作用下, 按最 
不利考虑制动力 $T$ 由 2 片横抬梁承担, 考虑不均匀系数 1.2 , 则 分配到单片横抬梁上的制动力 $T_{1}=1.2 \times 123.8 / 2=74.28 \mathrm{kN}$ 。标准 组合下作用在横抬梁顶部支反力 $N_{1}=2 \times 673.7=1347.4 \mathrm{kN}$ 。横抬 梁抗倾覆计算图式如图 6 所示。

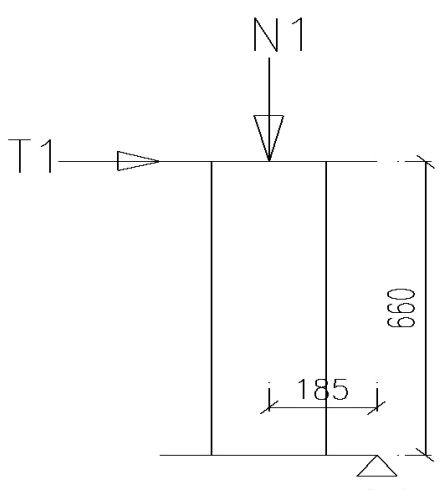

转动点

图 6 横抬梁抗倾覆计算图式 (单位: $\mathrm{mm}$ )

横抬梁抗倾覆稳定系数 $\lambda=\left(0.185 \cdot N_{1}\right) /\left(0.66 \cdot T_{1}\right)=5.08>$ 2.0 。双线列车荷载作用下, 按最不利考虑制动力 $T$ 由 2 片横 抬梁支撑, 考虑不均匀系数 1.2 , 则分配到单片横抬梁上的制 动力 $T_{1}=(2 \times 1.2 \times 123.8) / 2=148.56 \mathrm{kN}$ 。标准组合下作用在横抬 梁顶部支反力 $N_{1}=4 \times 673.7=2694.8 \mathrm{kN}$ 。横抬梁抗倾覆稳定系数 $\lambda=5.08>2.0$, 则抗倾覆满足规范要求。

3.2 .3 标准组合下纵梁稳定性分析

根据上述计算结果, 梁横端部最大剪力: $F_{\mathrm{V}}=56.5 \mathrm{kN}$, 中间 横梁端部最大剪力: $F_{\mathrm{V}}=75.4 \mathrm{kN}$ 。根据纵梁板单元网格划分结 果: 每个接触面按 28 个节点荷载考虑, 则端横梁每个节点荷 载 $f=2.02 \mathrm{kN}$ 。纵梁底部与横抬梁连接处通过螺栓连接, 接触面 积取 $0.3 \mathrm{~m} \times 0.45 \mathrm{~m}$, 模型中按铰接处理。利用 Midas $/$ Fea3 .0 建 立纵梁板单元模型如图 7 所示。

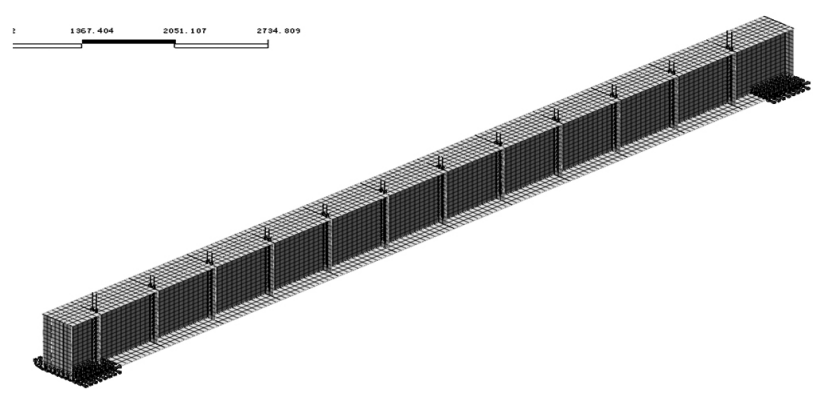

图 7 纵梁板单元模型离散图

由图 7 可知,标准组合下,纵梁最大坚向位移为 $4.07 \mathrm{~mm}$, $\mathrm{TOP}$ 面最大范梅塞斯应力为 $308.2 \mathrm{MPa}$, TOP 面最大剪应力为 $151.7 \mathrm{MPa}$ 。BOT 面最大范梅塞斯应力为 $293.8 \mathrm{MPa}$, BOT 面最 大剪应力为 $148.0 \mathrm{MPa}$, 纵梁最大主压应力为 $461.7 \mathrm{MPa}$ 。标准 组合下纵梁一阶屈曲稳定系数为 7.11 大于经验系数 4.0 , 则 整体稳定性满足要求。

\section{4 结语}

通过计算分析 D 型新施工简支便梁结构研究发现: (1)对 于单跨 $9 m$ 简支便梁支撑位置处易出现应力集中现象，应适当 加强纵梁支撑位置处构造措施 ${ }^{[3]}$ 。(2)在横抬梁与桩顶连接位 置、横抬梁与纵梁连接处, 建议加密肋板设置、施工便梁两端 应设置不小于 $10 \mathrm{~m}$ 的便梁过渡段, 以保证施工便梁内力的有 效传递。

\section{参考文献}

[1]景明.运梁车作用下桥建组合地铁车站受力分析与监测 [J].铁 道建筑,2018,58(11):57-61.

[2]沈李. 窄基角钢塔重力二阶效应力学分析与结构研究 [D]. 合 肥:合肥工业大学, 2018 .

[3]陶庆东, 刘跃国. 体内体外混合预应力配束连续刚构桥力学性 能对比分析[J].施工技术,2017,46(2):63-68 